\title{
Casein kinase 2 inhibition modulates the DNA damage response but fails to radiosensitize malignant glioma cells
}

\author{
JÉRÔME KROONEN $^{1 *}$, MARIA ARTESI ${ }^{1 *}$, VALÉRIE CAPRARO ${ }^{1}$, MINH-TUAN NGUYEN-KHAC $^{2}$, \\ MARIE WILLEMS ${ }^{1}$, ARNAB CHAKRAVARTI ${ }^{3}$, VINCENT BOURS ${ }^{1}$ and PIERRE A. ROBE ${ }^{1,3,4}$ \\ Departments of ${ }^{1}$ Human Genetics and GIGA Research Center, ${ }^{2}$ Neurosurgery, University of Liège, \\ 4000 Liege, Belgium; ${ }^{3}$ Department of Radiation Oncology and James Comprehensive Cancer Center, \\ Ohio State University, Columbus, OH 43210, USA; ${ }^{4}$ Department of Neurosurgery and Integrated \\ Cancer Center, University Medical Center of Utrecht, 3584 CX Utrecht, The Netherlands
}

Received February 9, 2012; Accepted March 23, 2012

DOI: $10.3892 /$ ijo.2012.1489

\begin{abstract}
Inhibitors of casein kinase 2(CK2), a regulator of cell proliferation and mediator of the DNA damage response, are being evaluated in clinical trials for the treatment of cancers. Apigenin was capable of inhibiting the activation of CK2 following $\gamma$ irradiation in LN18 and U87 malignant glioma cells. Apigenin and siRNA-mediated CK2 protein depletion further inhibited NF- $\mathrm{NB}$ activation and altered the Tyr68 phosphorylation of Chk2 kinase, a DNA damage response checkpoint kinase, following irradiation. However, CK2 inhibition did not decrease the ability of these glioma cells to repair double-strand DNA breaks, as assessed by COMET assays and $\gamma$-H2Ax staining. Likewise, apigenin and siRNA-induced depletion of CK2 failed to sensitize glioma cells to the cytotoxic effect of 2 to 10 G-rays of $\gamma$ irradiation, as assessed by clonogenic assays. These results contrast with those found in other cancer types, and urge to prudence regarding the inclusion of malignant glioma patients in clinical trials that assess the radiosensitizing role of CK2 inhibitors in solid cancers.
\end{abstract}

\section{Introduction}

Malignant astrocytomas represent the most frequent type of malignant brain tumors and are characterized by a strong resistance to therapies and a dismal prognosis (1). Among the factors that determine this resistance to treatment, anti-apoptotic signaling, for instance through constitutive NF- $\kappa \mathrm{B}$ pathway activation $(2,3)$, and altered DNA-damage response (4), are believed to play major roles.

Correspondence to: Dr Pierre A. Robe, Department of Neurosciences, Division of Neurosurgery, University Medical Center of Utrecht, 100 Heidelberglaan, 3584 CX Utrecht, The Netherlands E-mail: p.robe@umcutrecht.nl

*Contributed equally

Key words: glioblastoma, radiation therapy, casein kinase 2
Casein kinase 2 (CK2), an ubiquitous serine threonine kinase, consists of tetramers of 2 catalytic and 2 regulatory subunits. It has recently gained interest in the field of cancer research as both a regulator of proliferation and survival pathways and a modulator of the DNA-repair machinery $(5,6)$. CK2 was thus shown to regulate NF- $\mathrm{NB}$ and STAT3 activation, P53 function (7), PTEN activity, Akt-dependant signaling, mTOR stability and SIRT-dependent protein acetylation (6,8-13). CK2 also regulates the function of several enzymes of the DNA-repair and DNA-damage sensing machinery, such as XRCC1 and 4, Rad9 and DNA-PK (14-16). As a corollary, pre-clinical studies have shown that $\mathrm{CK} 2$ inhibitors elicit anti-tumoral effects against leukemias, prostate carcinomas, breast cancers, and some PTEN or TP53 mutated malignant gliomas $(17,18)$. Based on these reports, CK2 inhibitors entered the field of clinical trials (8,19-22). Among them, apigenin is a naturally occurring plant flavonoid and a specific inhibitor of the catalytic subunits of CK2 $(8,23,24)$. It was shown to reduce the proliferation and to induce apoptosis in several carcinoma cells (25-27) as well as in some human glioma cell lines (28), and has recently been used in a phase II trial for the prevention of colorectal cancer recurrence (NCT00609310).

Given this growing interest of clinicians and the industry for CK2 inhibitors, and in view of the fundamental yet disappointing role of radiation therapy for the treatment of malignant gliomas (1), we investigated whether CK2 inhibition would alter the radiation-induced DNA repair response and whether these tumors could be radiosensitized.

\section{Materials and methods}

Cell cultures, reagents and siRNA. Cell lines U87 and LN18 were obtained from the American Type Culture Collection (ATCC) and grown in DMEM (Dulbecco's modified Eagle's medium, Gibco, Gent, Belgium) containing $10 \%$ of fetal bovine serum (FBS, Gibco) and penicillin. Cultures were maintained at $37^{\circ} \mathrm{C}$ under a humidified atmosphere containing $5 \%$ carbon dioxide.

Apigenin was purchased from Sigma (Bornem, Belgium), dissolved in dimethylsulfoxide (DMSO) and used at final concentration of $40 \mu \mathrm{M}$ (stock solution, $100 \mathrm{mM}$ ). Control cells were treated with a similar final concentration of DMSO as the 
apigenin-treated cells. Irradiations of cell lines were conducted with a research irradiator (Gammacell 40 Exactor, Theratronics, Stockley Park, UK).

Subconfluent cultured cells were transfected with $50 \mathrm{nmol} / 1$ ON-TARGETplus non-targeting pool or SMARTpool human CSNK2A1 siRNA from Dharmacon (Fisher Scientific, Tournai, Belgium) using oligofectamine (Invitrogen, Gent, Belgium) according to the manufacturer's instructions. Cells were harvested and assayed $48 \mathrm{~h}$ after transfection. CK2 depletion was controlled using western blot analysis of the expression of CK2- $\alpha$.

$C K 2$ and IKK- $\beta$ kinase assays. Cells were lysed using RIPA buffer extraction kit (Santa Cruz Biotechnology) and $300 \mu \mathrm{g}$ of protein were taken for immunoprecipitation. After a pre-cleared step, supernatant were incubated with an anti-CK2 antibody (clone 1AD9, Millipore, Overijse, Belgium) under rotary agitation for $4 \mathrm{~h}$ at $4^{\circ} \mathrm{C}$. GammaBind G Sephorase beads (25 $\mu \mathrm{l} /$ samples, GE Healthcare, Diegem, Belgium) were then added to the sample and incubated on a rotating system overnight at $4^{\circ} \mathrm{C}$. After three washes, immunoprecipitated proteins were processed with the CK2 assay kit (Upstate, Millipore) or the IKK- $\beta$ kinase assay kit (Cell Signaling, Bioke, Leiden, The Netherlands), according to the manufacturer's instructions.

$N F-\kappa B$ transcription assay. Cells were co-transfected by using TransIT-2020 transfection reagent (Mirus, Eke, Belgium) with: i) a luciferase-coupled reporter gene for $\mathrm{NF}-\kappa \mathrm{B}$ and ii) a Renilla luciferase reporter driven by a constitutive promoter. Radiation $(10 \mathrm{~Gy})$ and apigenin treatment $(40 \mu \mathrm{M})$ effects on $\mathrm{NF}-\kappa \mathrm{B}$ transcriptional activity were assessed $24 \mathrm{~h}$ later. Briefly, cells were lysed and luciferase activities were measured according to the manufacturer's instructions for the Dual Luciferase Assay System (Promega, Leiden, The Netherlands) and using a Victor luminometer (PerkinElmer, Zaventem, Belgium). The relative $\mathrm{NF}-\kappa \mathrm{B}$ luciferase activity was normalized to the one of the Renilla.

Western blot analysis. $10 \%$ polyacrylamide precast gels (Mini Protean TGX, Bio-Rad, Nazareth Eke, Belgium) were run for $30 \mathrm{~min}$ at 200 volts with nuclear extract $(20 \mu \mathrm{g} /$ well $)$ obtained from irradiated and previously apigenin or DMSO treated cells. Protein extracts were obtained using conventional RIPA buffer and phosphatase inhibitors. After transfer to a PVDF membrane (Roche, Vilvoorde, Belgium) for $2 \mathrm{~h}$ at $300 \mathrm{~mA}$ and blocking with Tris buffered saline containing $0.2 \%$ Tween plus $5 \%$ dry milk powder, membranes were incubated overnight at $4^{\circ} \mathrm{C}$ in the presence of primary antibody directed against phospho(Thr68)Chk2 (Cell Signaling, Bioké, Leiden, The Netherlands). A horseradish peroxidase-coupled secondary antibody was then incubated, and peroxidase activity was evidenced with the Super Signal West Pico Chemiluminescent substrate (Thermo Fisher Scientific, Aalst, Belgium) and the ImageQuant LAS 4000 Mini Biomolecular Imager (GE Healthcare).

Cell survival assays. Cell survival in response to apigenin treatment and radiation was assayed using clonogenic assays and MTS tests (One Solution Cell Proliferation Assay, Promega). Clonogenic assays were performed on cells plated at low-density as described previously (29) and as recommended by the manufacturer's protocol for MTS assays.
DNA repair assays. Single-cell gel electrophoresis under alkaline conditions and flow cytometry measurement of phosphorylated $\gamma$-histone $2 \mathrm{Ax}(\gamma-\mathrm{H} 2 \mathrm{Ax})$ foci were used to identify ds-DNA breaks and associated repair mechanisms, respectively.

ds-DNA breaks following apigenin (or DMSO) treatment and radiation were detected by using the CometAssay HT kit (Trevigen, Sanbio, Uden, The Netherlands). Briefly, single cells embedded in agarose were lysed to remove proteins and where then submitted to electrophorese. Staining was performed with SYBR green I (Trevigen) for $15 \mathrm{~min}$. The slides were examined under a fluorescent microscope (Zeiss Axiovert 10 microscope, Carl Zeiss) and DNA tail lengths were quantified in a blinded manner by counting a minimum of 50 cells per condition in independent experiments.

Treated cells were harvested at different times and were prepared for flow cytometer analysis. Approximately $2.5 \times 10^{6}$ cells $/ \mathrm{ml}$ were resuspended in $250 \mu \mathrm{l}$ of PBS and fixed by adding the same amount of $4 \%$ paraformaldehyde (PFA, Merck, Overijse, Belgium). After permeabilization and blocking with PBS containing 0.5\% Triton X-100 (Acros Organics, Geel, Belgium) and 5\% donkey serum (Jackson Immunoresearch Laboratories, Newmarket, UK) for $20 \mathrm{~min}$, an anti-phosphorylated Ser139 $\gamma$-H2Ax mouse monoclonal antibody (1:500, Millipore) was incubated for $90 \mathrm{~min}$ at room temperature. Three PBS washes later, we incubated cells with an FITCconjugated secondary antibody (1:500, Jackson Immunoresearch Laboratories). Indirect immunofluorescence staining was immediately analyzed after three more PBS washes (FACS Calibur, BD Biosciences, Erembodegem, Belgium).

Statistical analysis. Statistical analyses were performed using the Prism 5.0c for Mac software (Graphpad Inc., La Jolla, CA). One-way ANOVA and Mann-Whitney U tests were performed when appropriate and as described in the results section.

\section{Results}

Irradiation-induced CK2 kinase activity in malignant glioma cells. Exposure of LN18 and U87 cells to ionizing radiations ( $\gamma$ rays, $4 \mathrm{~Gy}$ ) increased the catalytic activity of CK2 within $30 \mathrm{~min}$, by respectively $25 \pm 5 \%$ and $45 \pm 2.5 \%$. Both the basal and radiation-induced CK 2 activities were significantly abolished by pretreatment of the cell cultures with $40 \mu \mathrm{M}$ Apigenin for $1 \mathrm{~h}$ (mean $\pm \mathrm{SD}, \mathrm{n}=3, \mathrm{P}<0.05$ for both, ANOVA with Tukey's post tests; Fig. 1).

Irradiation-induced $N F-\kappa B$ activation in malignant glioma cells. Ionizing radiation activates $\mathrm{NF}-\kappa \mathrm{B}$ in tumors and glioblastomas via an ATM-NEMO-IKK-kinase dependent pathway (30). UV-induced DNA damage, however, also activates CK2 (31), leading to an IKK-kinase-independent C-terminal phosphorylation and degradation of $\mathrm{I}-\kappa \mathrm{B} \alpha$, and $\mathrm{NF}-\kappa \mathrm{B}$ activation (32). In LN18 and in U87 cells, ionizing irradiation (10 Gy) increased within $1 \mathrm{~h}$ the activity of an NF- $\kappa \mathrm{B}$-driven luciferase reporter gene by $31 \pm 6.6 \%$ and $66 \pm 34 \%$, respectively, (mean $\pm \mathrm{SD}, \mathrm{n}=3, \mathrm{P}<0.05$, one-way ANOVA with Tukey's post tests). The baseline activity of the reporter gene was inhibited following apigenin treatment and remained significantly reduced in these cells despite irradiation ( $\mathrm{P}<0.05,40 \mu \mathrm{M}$, Fig. 2). 


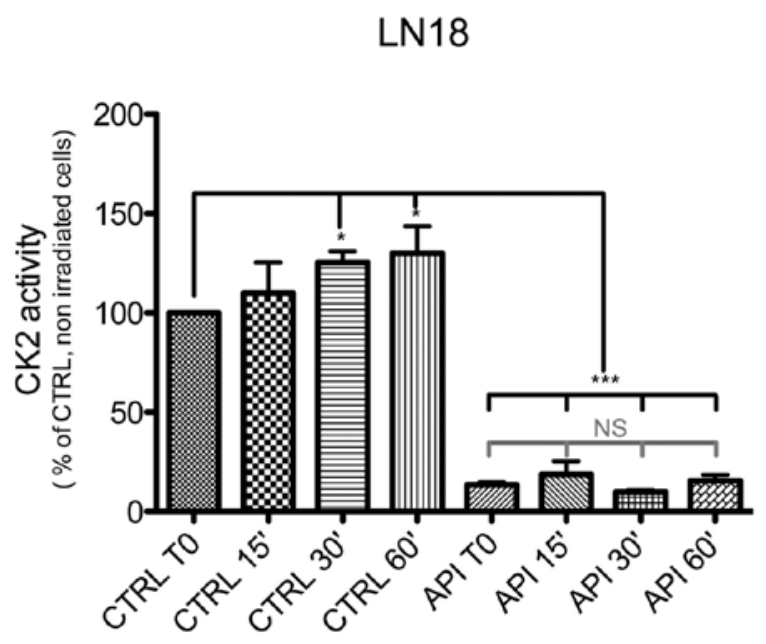

U87

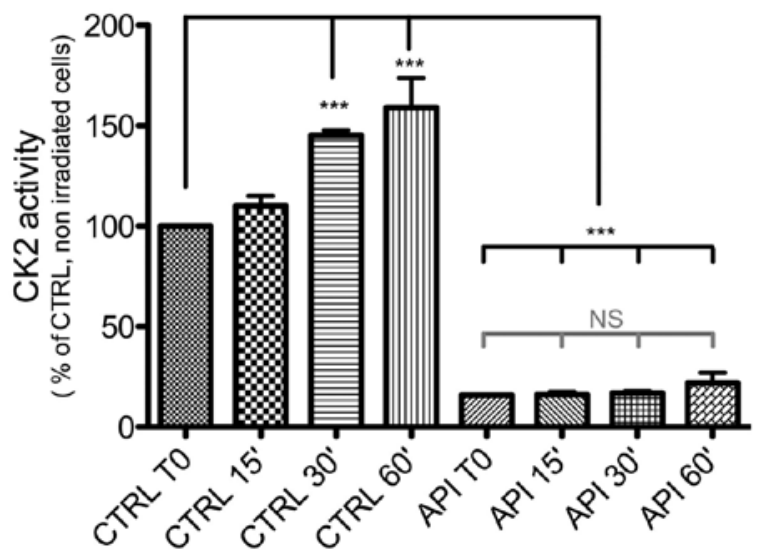

Figure 1. CK2 kinase assays following irradiation. LN18 and U87 cells were irradiated (4 Gy), homogenized and assessed for CK2 kinase activity following immunoprecipitation of the CK2 complex, as explained in the Materials and methods section. CTRL, cells are treated with DMSO only; API, cells are treated with $40 \mu \mathrm{M}$ apigenin in DMSO, for $1 \mathrm{~h}$ prior to the irradiation. Experiments are represented as percents of control, non-irradiated cells (T0), and as the mean $\pm \mathrm{SD}$ of 3 independent experiments. $\left({ }^{*} \mathrm{P}<0.05 ;{ }^{* * *} \mathrm{P}<0.001\right.$, ANOVA with Tukey's post tests).

CK2 inhibition and DNA-repair in malignant glioma cells. CK2 has recently emerged as a regulator of the DNA damage response machinery (33). We thus performed COMET assays to measure the influence of CK2 inhibition on ds-DNA break formation in U87 and LN18 cells following $\gamma$ irradiation (10 Gy). As shown in Fig. 3A, si-mediated CK2 depletion slightly decreased the peak amplitude of COMET tails in LN18 cells $3 \mathrm{~h}$ following a $10 \mathrm{~Gy}$ irradiation $(\mathrm{P}<0.05$, Mann-Witney $\mathrm{U}$ test). It however had the opposite effect in U87 cells $(\mathrm{P}<0.05$, Mann-Witney $U$ test). The mean tail amplitude returned to baseline in mock-treated and siCK2-treated LN18 cells after $24 \mathrm{~h}$. Tail size also returned to baseline in siCK2-treated U87 cells, in sharp contrast to mocktransfected cells where tails still remained significantly longer than at baseline at this time point $(\mathrm{P}<0.0001$, Mann-Witney $\mathrm{U}$ test).

We also assessed the kinetics of $\gamma-\mathrm{H} 2 \mathrm{Ax}$ foci formation in LN18 and U87 cells treated with apigenin (40 $\mu \mathrm{M})$ using

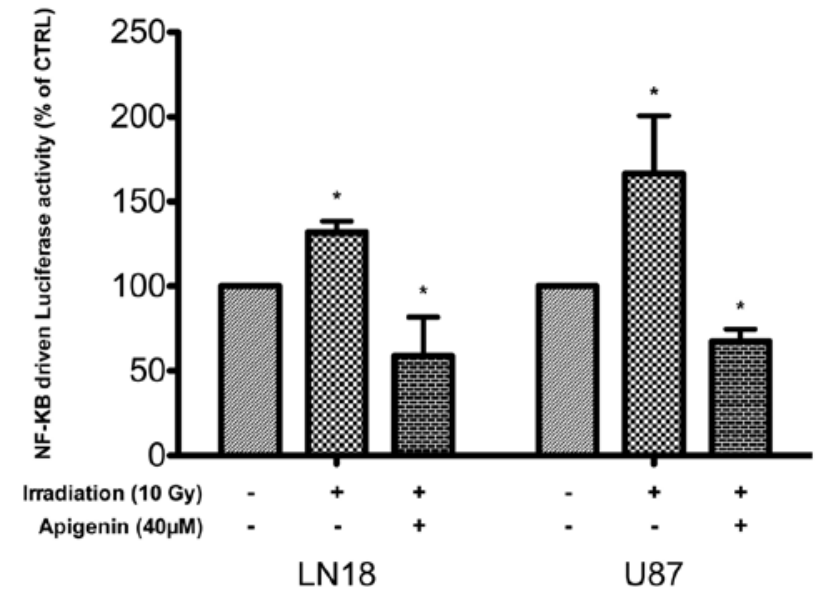

Figure 2. NF- $\kappa$ B reporter gene assays. NF- $\kappa \mathrm{B}$-driven luciferase activity was measured $1 \mathrm{~h}$ after irradiation (10 Gy) prior and after irradiation of LN18 and U87 cells in control (DMSO) conditions and following apigenin treatment. Activities are represented in percents of control, non-irradiated cells, and are shown as the mean \pm SD of 3 independent experiments $\left({ }^{*} \mathrm{P}<0.05\right.$, ANOVA with Tukey's post tests).

FACS cytometry. In both cell types, radiation treatment (10 Gy) increased the amount of $\gamma$-H2Ax immunoreactivity with respect to baseline conditions, with a peak within 1 to $3 \mathrm{~h} . \gamma-\mathrm{H} 2 \mathrm{Ax}$ signal returned towards baseline in control and apigenin-treated in both cell types within $24 \mathrm{~h}$. Apigenin treatment did not alter these post-irradiation kinetics of $\gamma$-H2Ax immunoreactivity (data not shown).

CK2 is also known to inhibit the DNA-repair kinase DNA-PK (15), and the Chk2 checkpoint kinase is phosphorylated on tyrosine 68 by DNA-PK following irradiation (34). Tyr68 phosphorylation of Chk2 was induced in LN18 and U87 within 15 min after irradiation (4 Gy). This event was potentiated and more durable in both cell types by a pre-treatment with $40 \mu \mathrm{M}$ apigenin (Fig. 3B).

CK2 inhibition and cell survival following $\gamma$ irradiation. Both U87 and LN18 cells displayed a moderate but significant reduction in viability following 4 G-rays of $\gamma$ irradiation $(25.5 \pm 13.2 \%$ and $27 \pm 19.5 \%$, respectively, $\mathrm{P}<0.05$, one-way ANOVA) as assessed using an MTS test (Fig. 4A). This viability was not further reduced following co-treatment with $40 \mu \mathrm{M}$ apigenin. At this concentration, apigenin treatment also failed to radiosensitize U87 and LN18 cells in clonogenic assays (Fig. 4B, upper pannel).

As CK2-independent effects of apigenin have been reported (35), we also assessed the effect of siRNA-mediated CK2 kinase depletion on the radiosensitization of malignant glioma cells. The clonogenic survival of U87 and LN18 cells treated with CK2-targetting siRNA prior to irradiation did not differ from scramble siRNA treated controls (Fig. 4B, lower pannel).

\section{Discussion}

CK2 has recently appeared as a regulator of ds-DNA break (DSB)-triggered signaling cascades in normal, carcinoma and even in some malignant glioma cells (36). 
A
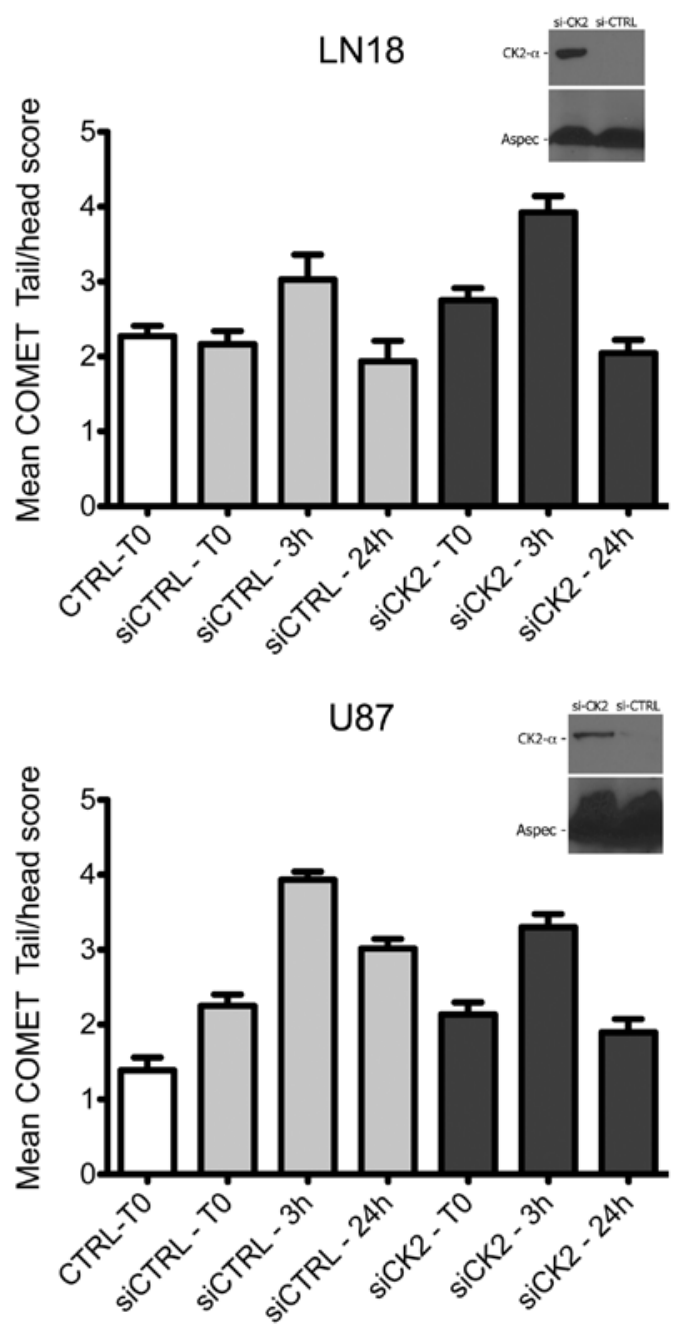

Accordingly, CK2- $\alpha$, the active kinase subunit of CK2, was activated within minutes of radiation treatment in our malignant glioma cells. siRNA-mediated CK2 depletion significantly increased the maximal peak of DSB in LN18 cells, but not in U87 cells. However, CK2 knock-down did not inhibit the repair of ds-DNA breaks in our cell lines, but even slightly improved it, as evidenced by the normalization of COMET assays within $24 \mathrm{~h}$ after irradiation in both cell lines and the faster return of $\gamma$-H2Ax immunoreactivity towards the baseline in U87 cells following apigenin treatment.

In standard conditions, homologous recombination (HR) only plays an accessory role in ds-DNA repair following ionizing radiation in gliomas, and these tumors rather proceed via non-homologous end joining (NHEJ) (37). During NHEJ, CK2 phosphorylates XRCC4 and helps recruit repair enzymes like PNKP and APLF to this scaffold protein $(13,15,36,38,39)$. According to this, and in contrast to our COMET and $\gamma-\mathrm{H} 2 \mathrm{Ax}$ findings, CK2 inhibition should thus inhibit DNA repair. In better agreement with our results however, CK2 inhibition did not impair ds-DNA rejoining in fibroblasts or colon carcinoma cells (40). As a tentative explanation, CK2 also inhibits the DNA-dependent protein kinase subunit DNA-PKcs in glioblastomas (15). DNA-PK is itself a key inhibitor of HR (41), and gliomas might thus escape CK2 inhibition-induced NHEJ inhibition via an increase in homologous recombination. In agreement with this hypothesis, apigenin treatment of glioma cells increased the radiation-induced phosphorylation of the DNA-PK target Chk2 $(34,42)$ in our experiments.

In colon carcinoma cells and fibroblasts, although CK2 inhibition does not alter the rejoining of DSB, it does slow down

B

LN18
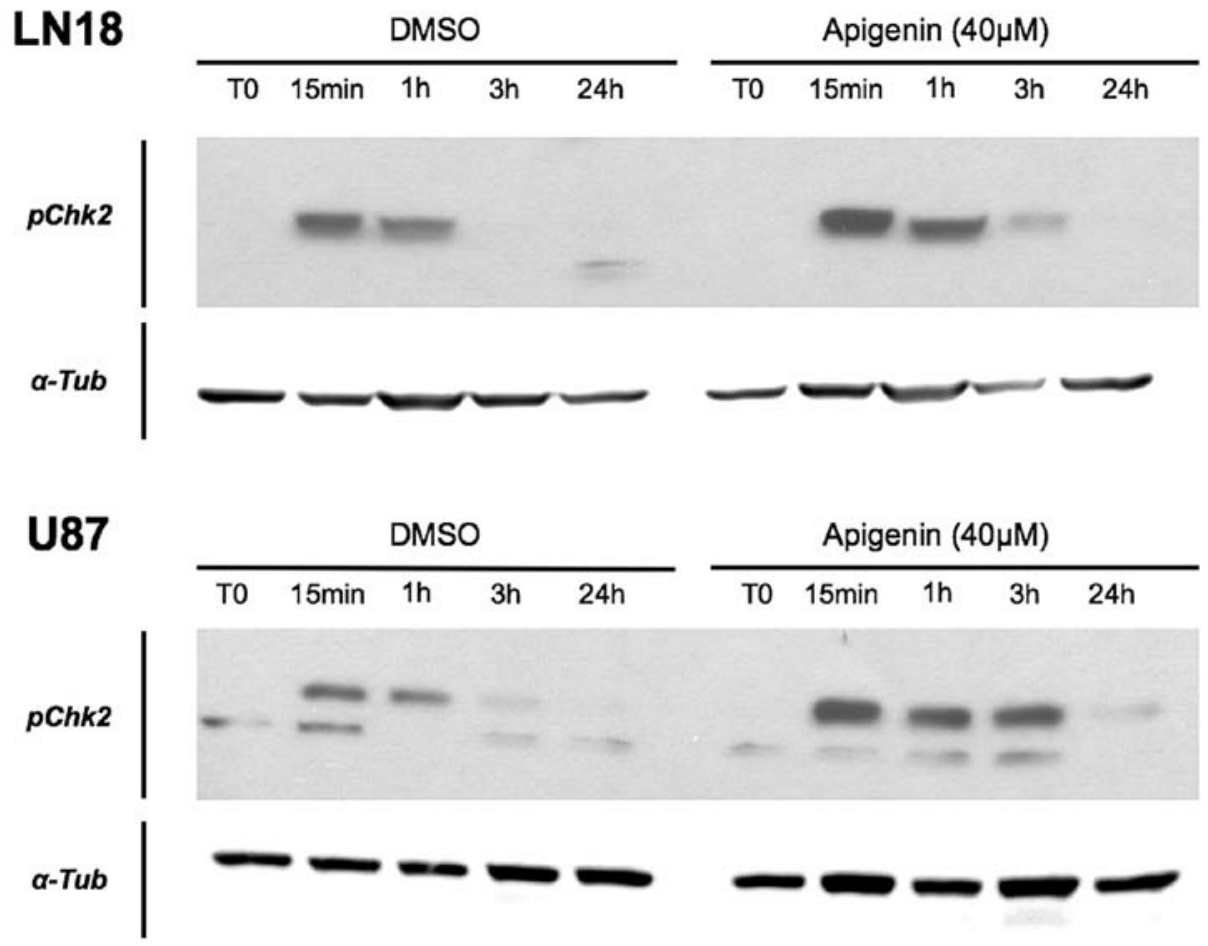

Figure 3. CK2 inhibition and DSB-repair. (A) COMET assays were performed on glioma cells transfected with siRNA to CK2 or control scramble siRNAs, and then irradiated $(10 \mathrm{~Gy})$. ds-DNA break formation was determined $3 \mathrm{~h}$ and $24 \mathrm{~h}$ after the irradiation. COMET tail/head ratios are shown as the means $\pm \mathrm{SD}$ of a minimum of 50 cells $\left(\right.$ ( $\mathrm{P}<0.05 ;{ }^{* * * *} \mathrm{P}<0.0001$, Mann-Witney $\mathrm{U}$ test). (Inserts): Western blot analysis of the inhibition of CK2- $\alpha$ expression $48 \mathrm{~h}$ after the siRNA transfection. (B) Western blot analysis of Tyr68 phosphorylation of CK 2 in U87 and LN18 cells following irradiation (4 Gy) and apigenin treatment (40 $\mu \mathrm{M})$. 
A

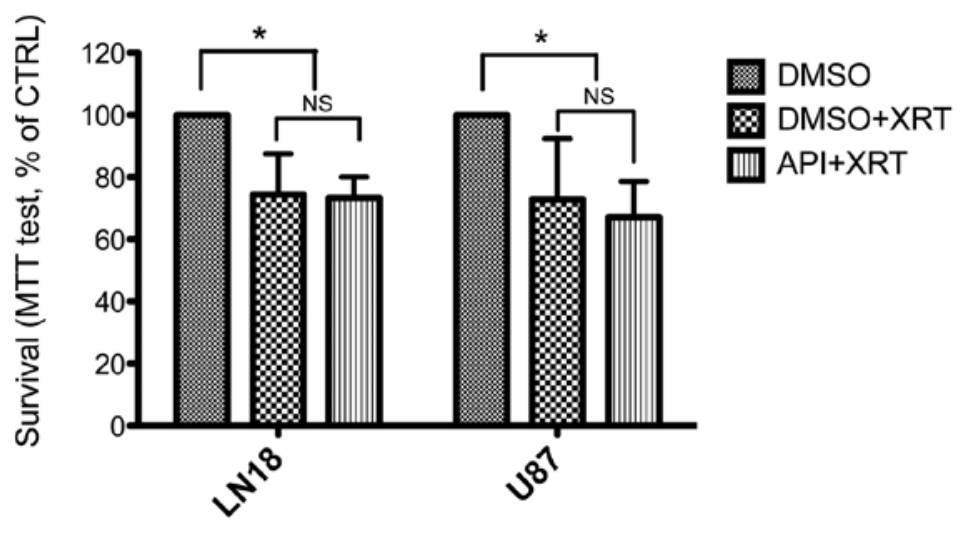

B
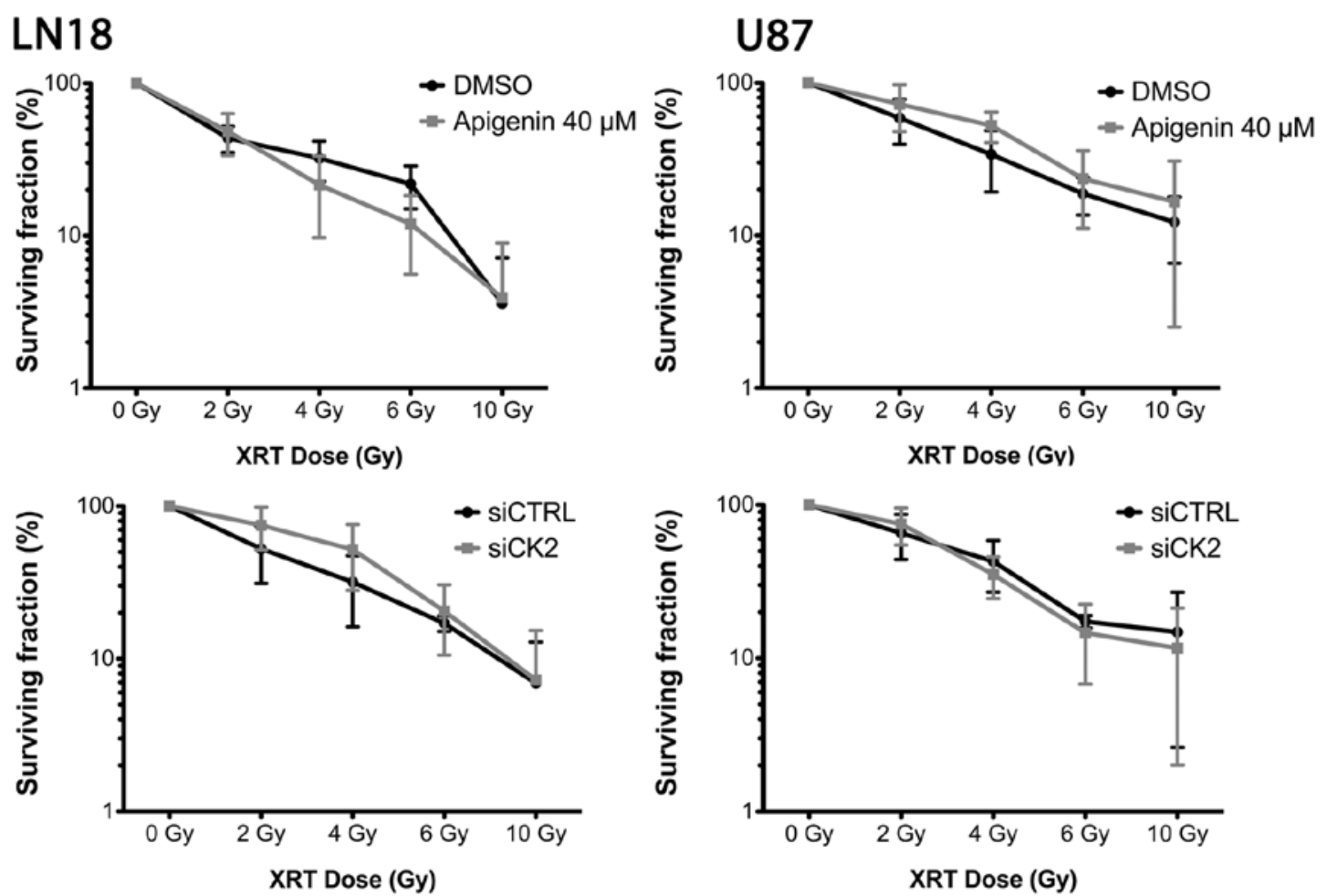

Figure 4. CK2 inhibition and survival of glioma cells following irradiation. (A) MTS proliferation assays were performed 5 days after a 4 Gy irradiation (XRT) following a $1 \mathrm{~h}$ pre-treatment with $40 \mu \mathrm{M}$ apigenin. Experiments are represented in percents of control, non-irradiated cells, and as the mean $\pm \mathrm{SD}$ of 3 independent experiments ("P<0.05, ANOVA with Newman-Keuls post tests). (B) Clonogenic assays of LN18 And U87 cell survival 9 days after irradiation (2, 4, 6 and 10 Gy) in the presence or not of apigenin (upper panel) or after CK2- $\alpha$ depletion (lower pannel). Results are expressed in percents of controls, non-irradiated cells and as the mean \pm SD of 4 independent experiments.

the dephosphorylation of $\gamma$-H2Ax and its dissociation from the DNA after repair (40). Such a lengthened $\gamma$-H2Ax decay is believed to amplify checkpoint signaling in the presence of minimal residual DNA damage and lead to cell death (43). We did not observe this phenomenon in our experiments.

In our experiments and in agreement with previous reports $(44,45)$, CK2 inhibition also reduced the constitutive level of $\mathrm{NF}-\kappa \mathrm{B}$ reporter activity in both cell lines. The postradiation transcriptional activity of this factor also remained significantly lower in apigenin-treated irradiated cells than in the control, non-irradiated cells. Apigenin-treated cells, however, still responded to irradiation with a minimal induction of NF- $\mathrm{NB}$ (data not shown), and our results thus do not contradict the paradigm that $\mathrm{CK} 2$ triggers $\mathrm{NF}-\kappa \mathrm{B}$ activation in response to UV-induced DNA damage but not following exposure to ionizing radiation (46-49).

Pharmacological NF- $\kappa \mathrm{B}$ inhibitors are nonetheless known to modulate the fate of tumor cells following irradiation. They were reported to radiosensitize glioblastomas $(50,51)$, but NF- $\kappa \mathrm{B}$ was also, on the contrary, recently reported to mediate apoptosis following the irradiation of primary cultures and progenitor cells of gliomas lines (52). In line with these contrasting reports and its favorable effect on DSB-repair in our experiments, CK2 inhibition did not radiosensitize our glioma cells. This neutrality seems to be independent of TP53 mutational status, as we confirmed by exon sequencing that LN18 and U87 cells express, respectively mutant and wild-type variants of this CK2 target (data not shown) (53-55). Aspecific effects of apigenin were 
also ruled out by repeating clonogenic assays following siRNA mediated depletion of CK2- $\alpha$.

Although we cannot rule out that $\mathrm{CK} 2$ inhibition could radiosensitize glioblastoma cells with defective DNA-PK, the lack of radiosensitization of gliomas that we have observed contrasts with that of non-small cell lung carcinomas, fibroblasts and colon carcinomas cells following CK2 inhibition (6,40). Since DNA-PK mutations occur in only $3 \%$ of glioblastomas (TCGA data portal, accessed January 16th, 2011; the TCGA research network) (56) we believe that glioma patients should not be included in clinical trials that assess the radiosensitizing role of CK2 inhibitors. Further studies of DNA repair mechanisms in primary brain tumors and a preclinical evaluation of therapies combining CK2 inhibitor with other DNA-damaging agents with DNA-PK inhibitors are required to improve the therapeutic options for these tumors.

In spite of its modulation of DNA-damage signaling cascades, CK2 inhibition fails to inhibit DNA repair following ionizing radiation and to radiosensitize glioma cells, independently of their TP53 status. This contrasts with other tumor types, urging caution regarding the inclusion of malignant glioma patients in clinical studies that will assess the radiosensitizing role of CK2 inhibitors in solid cancers.

\section{Acknowledgements}

We wish to thank Dr Sandra Ormenese for her help with the flow cytometry, as well as Mr. Olivier Pierard and Ms. Catherine Waltener for their expert technical assistance.P.A.R. is a research associate at the Belgian Fund for Scientific Research. This study was supported by grant PNC 29-006 of the Belgian Ministry of Health to V.B. and P.A.R., grant 1.5.162.10 of the National Research Fund of Belgium to P.A.R., a grant from the Belgian Foundation against Cancer to V.B. and P.A.R., and a grant from the Centre Anticancéreux of the University of Liège to V.B.

\section{References}

1. Stupp R, Mason WP, van den Bent MJ, et al: Radiotherapy plus concomitant and adjuvant temozolomide for glioblastoma. N Eng J Med 352: 987-996, 2005.

2. Robe PA, Bentires-Alj M, Bonif M, et al: In vitro and in vivo activity of the nuclear factor-kappaB inhibitor sulfasalazine in human glioblastomas. Clin Cancer Res 10: 5595-5603, 2004.

3. Bredel M, Scholtens DM, Yadav AK, et al: NFKBIA deletion in glioblastomas. N Engl J Med 364: 627-637, 2011.

4. Squatrito M and Holland EC: DNA damage response and growth factor signaling pathways in gliomagenesis and therapeutic resistance. Cancer Res 71: 5945-5949, 2011.

5. Becherel OJ, Jakob B, Cherry AL, et al: CK2 phosphorylationdependent interaction between aprataxin and MDC1 in the DNA damage response. Nucleic Acids Res 38: 1489-1503, 2010.

6. Lin YC, Hung MS, Lin CK, et al: CK2 inhibitors enhance the radiosensitivity of human non-small cell lung cancer cells through inhibition of stat 3 activation. Cancer Biother Radiopharm 26 : 381-388, 2011.

7. Brown MS, Diallo OT, Hu M, et al: CK2 modulation of NF-кB, TP53, and the malignant phenotype in head and neck cancer by anti-CK2 oligonucleotides in vitro or in vivo via Sub-50-nm nanocapsules. Clin Cancer Res 16: 2295-2307, 2010.

8. Eddy SF, Guo S, Demicco EG, et al: Inducible IkappaB kinase/ IkappaB kinase epsilon expression is induced by CK2 and promotes aberrant nuclear factor-kappaB activation in breast cancer cells. Cancer Res 65: 11375-11383, 2005.

9. Yu M, Yeh J and Van Waes C: Protein kinase casein kinase 2 mediates inhibitor-kappaB kinase and aberrant nuclear factorkappaB activation by serum factor(s) in head and neck squamous carcinoma cells. Cancer Res 66: 6722-6731, 2006.
10. Siepmann M, Kumar S, Mayer G and Walter J: Casein kinase 2 dependent phosphorylation of neprilysin regulates receptor tyrosine kinase signaling to Akt. PLoS One 5: E13134, 2010.

11. Horejsí Z, Takai H, Adelman CA, et al: CK2 phospho-dependent binding of R2TP complex to TEL2 is essential for mTOR and SMG1 stability. Mol Cell 39: 839-850, 2010

12. Maccario H, Perera NM, Davidson L, Downes CP and Leslie NR: PTEN is destabilized by phosphorylation on Thr366. Biochem J 405: 439-444, 2007.

13. Kang H, Jung JW, Kim MK and Chung JH: CK2 is the regulator of SIRT1 substrate-binding affinity, deacetylase activity and cellular response to DNA-damage. PLoS One 4: E6611, 2009.

14. Takeishi Y, Ohashi E, Ogawa K, Masai H, Obuse $\mathrm{C}$ and Tsurimoto T: Casein kinase 2-dependent phosphorylation of human Rad9 mediates the interaction between human Rad9-Hus1-Rad1 complex and TopBP1. Genes Cells 15: 761-771, 2010.

15. Olsen BB,Issinger OG and Guerra B: Regulation of DNA-dependent protein kinase by protein kinase CK2 in human glioblastoma cells. Oncogene 29: 6016-6026, 2010.

16. Ström CE, Mortusewicz O, Finch D, et al: CK2 phosphorylation of XRCC1 facilitates dissociation from DNA and single-strand break formation during base excision repair. DNA Repair 10: 961-969, 2011.

17. Kaminska B, Ellert-Miklaszewska A, Oberbek A, et al: Efficacy and mechanism of anti-tumor action of new potential CK 2 inhibitors toward glioblastoma cells. Int J Oncol 35: 1091-1100, 2009.

18. Prudent R, Moucadel V, Nguyen CH, et al: Antitumor activity of pyridocarbazole and benzopyridoindole derivatives that inhibit protein kinase CK2. Cancer Res 70: 9865-9874, 2010.

19. Pierre F, Chua PC, O'Brien SE, et al: Pre-clinical characterization of CX-4945, a potent and selective small molecule inhibitor of CK2 for the treatment of cancer. Mol Cell Biochem 356: 37-43, 2011.

20. Battistutta R, Cozza G, Pierre F, et al: Unprecedented selectivity and structural determinants of a new class of protein kinase CK2 inhibitors in clinical trials for the treatment of cancer. Biochemistry 50: 8478-8488, 2011.

21. Schneider CC, Hessenauer A, Montenarh M and Götz C: p53 is dispensable for the induction of apoptosis after inhibition of protein kinase CK2. Prostate 70: 126-134, 2010.

22. Shehata M, Schnabl S, Demirtas D, et al: Reconstitution of PTEN activity by CK2 inhibitors and interference with the PI3-K/Akt cascade counteract the antiapoptotic effect of human stromal cells in chronic lymphocytic leukemia. Blood 116: 2513-2521, 2010.

23. Li C, Liu X, Lin X and Chen X: Structure-activity relationship of 7 flavonoids on recombinant human protein kinase CK2 holoenzyme. Zhong Nan Da Xue Xue Bao Yi Xue Ban 34: 20-26, 2009.

24. Sarno S, de Moliner E, Ruzzene M, et al: Biochemical and threedimensional-structural study of the specific inhibition of protein kinase CK2 by [5-oxo-5,6-dihydroindolo-(1,2-a)quinazolin-7-yl] acetic acid (IQA). Biochem J 374: 639-646, 2003.

25. Zhao M, Ma J, Zhu HY, et al: Apigenin inhibits proliferation and induces apoptosis in human multiple myeloma cells through targeting the trinity of CK2, Cdc37 and Hsp90. Mol Cancer 10: $104,2011$.

26. Zhong Y, Krisanapun C, Lee SH, et al: Molecular targets of apigenin in colorectal cancer cells: involvement of p21, NAG-1 and p53. Eur J Cancer 46: 3365-3374, 2010.

27. Slusarz A, Shenouda NS, Sakla MS, et al: Common botanical compounds inhibit the hedgehog signaling pathway in prostate cancer. Cancer Res 70: 3382-3390, 2010.

28. Das A, Banik NL and Ray SK: Flavonoids activated caspases for apoptosis in human glioblastoma T98G and U87MG cells but not in human normal astrocytes. Cancer 116: 164-176, 2010.

29. Chakravarti A, Zhai GG, Zhang M, et al: Survivin enhances radiation resistance in primary human glioblastoma cells via caspase-independent mechanisms. Oncogene 23: 7494-7506, 2004.

30. Miyamoto S: Nuclear initiated NF- $\kappa$ B signaling: NEMO and ATM take center stage. Cell Res 21: 116-130, 2010.

31. Keller DM, Zeng X, Wang Y, et al: A DNA damage-induced p53 serine 392 kinase complex contains CK2, hSpt16, and SSRP1. Mol Cell 7: 283-292, 2001.

32. Tsuchiya Y, Asano T, Nakayama K, Kato T Jr, Karin M and Kamata H: Nuclear IKKbeta is an adaptor protein for IkappaBalpha ubiquitination and degradation in UV-induced NF-kappaB activation. Mol Cell 39: 570-582, 2010.

33. Cheung WL, Turner FB, Krishnamoorthy T, et al: Phosphorylation of histone $\mathrm{H} 4$ serine 1 during DNA damage requires casein kinase II in S. cerevisiae. Curr Biol 15: 656-660, 2005.

34. Li J and Stern DF: DNA damage regulates Chk2 association with chromatin. J Biol Chem 280: 37948-37956, 2005. 
35. Agullo G, Gamet-Payrastre L, Manenti S, et al: Relationship between flavonoid structure and inhibition of phosphatidylinositol 3-kinase: a comparison with tyrosine kinase and protein kinase $\mathrm{C}$ inhibition. Biochem Pharmacol 53: 1649-1657, 1997.

36. Koch CA, Agyei R, Galicia S, et al: Xrce4 physically links DNA end processing by polynucleotide kinase to DNA ligation by DNA ligase IV. EMBO J 23: 3874-3885, 2004.

37. Quiros S, Roos WP and Kaina B: Rad51 and BRCA2 - new molecular targets for sensitizing glioma cells to alkylating anticancer drugs. PLoS One 6: E27183, 2011.

38. Macrae CJ, McCulloch RD, Ylanko J, Durocher D and Koch CA APLF (C2orf13) facilitates nonhomologous end-joining and undergoes ATM-dependent hyperphosphorylation following ionizing radiation. DNA Repair 7: 292-302, 2008.

39. Iles N, Rulten S, El-Khamisy SF and Caldecott KW: APLF (C2orf13) is a novel human protein involved in the cellular response to chromosomal DNA strand breaks. Mol Cell Biol 27: 3793-3803, 2007.

40. Zwicker F, Ebert M, Huber PE, Debus J and Weber KJ: A specific inhibitor of protein kinase CK 2 delays gamma-H2Ax foci removal and reduces clonogenic survival of irradiated mammalian cells. Radiat Oncol 6: 15, 2011.

41. Neal JA and Meek K: Choosing the right path: does DNA-PK help make the decision? Mutat Res 711: 73-86, 2011.

42. Hill R and Lee PW: The DNA-dependent protein kinase (DNA-PK): more than just a case of making ends meet? Cell Cycle 9: 3460-3469, 2010.

43. Kinner A, Wu W, Staudt C and Iliakis G: Gamma-H2AX in recognition and signaling of DNA double-strand breaks in the context of chromatin. Nucleic Acids Res 36: 5678-5694, 2008

44. Shen J, Channavajhala P, Seldin DC and Sonenshein GE: Phosphorylation by the protein kinase CK2 promotes calpainmediated degradation of IkappaBalpha. J Immunol 167: 4919-4925, 2001.

45. Viatour P, Merville MP, Bours V and Chariot A: Phosphorylation

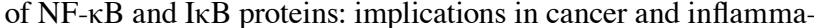
tion. Trends Biochem Sci 30: 43-52, 2005.
46. Janssens S and Tschopp J: Signals from within: the DNA-damageinduced NF-kB response. Cell Death Differ 13: 773-784, 2006

47. Kato $T$, Delhase M, Hoffmann $A$ and Karin M: CK2 is a C-terminal IkappaB kinase responsible for NF-kappaB activation during the UV response. Mol Cell 12: 829-839, 2003.

48. Li N: ATM is required for Ikappa B kinase (IKK) activation in response to DNA double strand breaks. J Biol Chem 276: 8898-8903, 2000.

49. Veuger SJ, Hunter JE and Durkacz BW: Ionizing radiation-induced NF- $\kappa \mathrm{B}$ activation requires PARP-1 function to confer radioresistance. Oncogene 28: 832-842, 2008

50. Hunter JE, Willmore E, Irving JAE, Hostomsky Z, Veuger SJ and Durkacz BW: NF- $\kappa$ B mediates radio-sensitization by the PARP-1 inhibitor, AG-014699. Oncogene 31: 251-264, 2012.

51. Tsuboi Y, Kurimoto M, Nagai S, et al: Induction of autophagic cell death and radiosensitization by the pharmacological inhibition of nuclear factor-kappa B activation in human glioma cell lines. J Neurosurg 110: 594-604, 2009.

52. Berger R, Jennewein C, Marschall V, et al: NF- $\kappa \mathrm{B}$ is required for Smac mimetic-mediated sensitization of glioblastoma cells for $\gamma$-irradiation-induced apoptosis. Mol Cancer Ther 10: 1867-1875, 2011.

53. Asai A, Miyagi Y, Sugiyama A, et al: Negative effects of wild-type p53 and s-Myc on cellular growth and tumorigenicity of glioma cells. Implication of the tumor suppressor genes for gene therapy. J Neurooncol 19: 259-268, 1994.

54. Wischhusen J, Naumann U, Ohgaki H, Rastinejad F and Weller M: CP-31398, a novel p53-stabilizing agent, induces p53-dependent and p53-independent glioma cell death. Oncogene 22: 8233-8245, 2003.

55. Meek DW and Cox M: Induction and activation of the $\mathrm{p} 53$ pathway: a role for the protein kinase CK2? Mol Cell Biochem 356: 133-138, 2011.

56. Cancer Genome Atlas Research Network: Comprehensive genomic characterization defines human glioblastoma genes and core pathways. Nature 455: 1061-1068, 2008. 